\title{
Radio As Ritual
}

\section{An Approach to Everyday Use of Radio}

\author{
Bent Steeg Larsen
}

Radio is the biggest medium in Denmark. Eighty-five per cent of all Danes over the age of 12 use radio daily, and the average Dane has his or her radio turned on over three hours each day. ${ }^{1}$ But, strangely enough, even though radio is used often and long hours, it does not make much of an impression in the consciousness of its users. Radio is a socalled secondary medium. It plays in the background while we do all kinds of other things (work, eat, clean the house, drive the car, etc.). Radio "is just there" - as takenfor-granted and regular a phenomenon as electric lights, water out of the tap, telephones and traffic lights. It is something we normally do not talk about, nor do we think much about radio in our everyday lives. Only when the receiver breaks down or disappears.

The secondary status of the medium in our lives makes it difficult to find out how people make use of radio. Of course, it does provide a lot of information which keep the listener abreast of happenings in society at large (news, weather reports, top ten lists, background information of vaious kinds, etc.), but radio as a source of information only covers the kind of uses when the radio is in the foreground of the user's consciousness. It does not cast light on the greater part of radio use, that which takes place when radio is in the background - the kind of use when we "hear" the radio rather than "listen" to it.

In this article I will offer some ideas about the functions radio may serve as a background medium, functions that are not directly related to, or dependent on the content the medium offers, but which rather have to do with its regularity and ability to set the mood. I wish to discuss whether, and in what ways, radio use is a ritual. Not the kind of ritual that surrounds notable events like moon landings, royal weddings, solar eclipses, and inaugurations of bridges, but the small rituals which take place in seemingly uneventful everyday life. There are many such rituals, and I shall argue that radio is involved in many of them.

My starting point is not that radio use itself is a ritual, but that the presence of radio and its sounds in various social situations help transform day-to-day activities into rituals. Rituals which integrate the participant(s) (the (user(s) of radio) into a social and cultural order which transcends the time and space of the particular situation. 
This may sound abstract, and I shall try to concretize my proposition with an example from an empirical study. I shall then proceed to examine some of the ways the concept of ritual has been applied to communication and media use. This review concludes with a specification of how the concept of ritual may be used in empirical studies, with inspiration from Durkheim and Goffman, among others. ${ }^{2}$

\section{Radio Use - Information and Integration}

When you ask heavy consumers of radio to explain their use of the medium, the first thing they will say is that they like to "keep up" with what is happening. Especially by listening regularly to the news. They want to know the traffic situation before they leave home, they want to be able to discuss current events with their workmates, and they feel that, as citizens with the right to vote in democratic elections, they have a duty to keep informed. ${ }^{3}$

Explanations like these are hardly surprising. It is a well-known fact that when one is asked to transform one's practical routines into a discursive consciousness, one tends to resort to accepted phrases which reproduce a stereotype of 'why we do what we do'. We say what the interviewer presumably expects to hear, namely, that the radio offers information that we put to some rational use. After all, one has to say something when the interviewer asks! ${ }^{4}$

But there are ways to get at the truth, to get past the stereotyped, ready-made responses. One way is to point out to the respondents that what they say they do does not always correspond with what they do. Users of radio say that the medium offers information. In doing so, they are articulating an implicit conception of media use as an individual act, a matter of 'text' and 'reader'. But when radio users at the same time relate the details of their hectic daily lives, only a fraction of what they listen to is 'pure' information. Radio use is largely determined by certain social and material preconditions in people's daily lives. These conditions are such that one cannot always assume that the medium is being used as a means of communication in the classic sense. In reality, users often do not focus their attention on the (information) content; they may be too far away to hear, and often someone else has chosen the station to begin with. Nor can people always decide when or how long they can use the radio. Use of radio is, in other words, to a large extent an integral part of everyday social activities.

My point is that radio use as 'information seeking' describes only some of the potential uses radio can be put to. For, even if users of radio say they do not always listen carefully to everything that comes out of the little box while it is turned on, most people would not be without it. "Something is missing," they say. The question is: What exactly is it that is missing? How do people use all the other content that is 'left over', so to speak, once we have sorted away all the 'pure' information?

\section{An Example}

The following example, taken from a qualitative study of radio's functions, is a good illustration of the day-to-day contexts in which radio use occurs. Anna tells of her family's - Anna, her husband and their two children - morning routines:

We have basically the same ritual, every morning, day in and day out. And pity the soul who falls out of step even a half second, for every minute you have in the morning... . I mean, our mornings run on a very tight schedule, especially if you are leaving the house ... and one of the first things we do is switch on the radio. (Anna) 
Anna describes a typical morning, when she and the rest of her family are in a hurry. All their tasks (washing, breakfast, dressing, etc.) are accomplished according to a strict time-table. Everyone is on his or her way to school or work. That is why, as Anna points out, there can be no deviations in the order things are done or the tempo. And radio? Quite symptomatically, Anna mentions radio last. This suggests that the demands of daily life come before use of the radio. The requirements of the major institutions (work, school, etc.) are what dictate media behaviour, not the media themselves.

But it may be wrong to speak of what comes 'before' what, the demands of life or media use. As I see it, use of radio is part of everyday life, an integral part of the daily routine, not something we turn to after all the more important tasks are out of the way. Perhaps it would be more accurate simply to say that we do not organize our days according to the media. Yet, the media form integral parts of our day-to-day existence in that they help to give routine tasks and behaviours a special character and content.

The very characteristic regularity of both media content and media use supports this idea. Most radio stations - and most mass media, for that matter - offer the same kinds of programmes at the same times in cycles of different lengths (days, weeks, months, years). Most radio use is also regularly scheduled; that is, we tune in to a given station at the same time each day, week, etc. Radio's familiar pattern of programming gives us the impression that the chaotic flow of events in the world are but variations within a fixed pattern, and that the same is true with respect to our own social and physical settings. ${ }^{5}$

Thus, we can say that Anna's use of the radio in the morning constitutes her day as a familiar place to be. She may not listen very much to the content - she is in a hurry but she notes that the radio is offering the same kinds of programmes it did the day before, so things must (thank Goodness!) be more or less 'business as usual'. The sound of the radio 'frames' her morning as a situation she is familiar with, one where she knows what she is doing, and is going to do next, and in what tempo. ${ }^{6}$

The interesting thing about Anna's statement, however, is that she speaks of her and her family's activities as a ritual. I argue that it actually is a ritual. It is, for example, a set of activities in which several people participate in a community that obliges them in one way or another. Note that radio use is not an individual activity, but something that involves more or less all the family members. Rituals are social in character, and the concept of ritual suggests an analysis of radio use as a social phenomenon, having effects above and beyond the actual media content, but in which the content most assuredly plays an important part.

To this we shall return. First, however, I should like to consider the term, 'ritual' and discuss some of the ways it has been applied in media research.

\section{The Concept of 'Ritual' in Communication and Media Research}

The concept of ritual has long been applied to mass media behaviour, but perhaps the most well-known example is James W Carey's (1989) distinction between communication as transmission and as ritual. Carey posits the two as alternative metaphors for communication (Carey 1989:14-15).

The transmission metaphor, which is the more common of the two, conceives of communication as the distribution of information in a spatial dimension. Here, communication is the transmission of 'content' from one place to another with the aim of influencing others' thoughts and actions. It is this aspect that users of radio mention first, and it is also what underlies earnest debates as to 'effects': whether or not exposure to 
commercials whets children's appetites for material consumption, whether serial fiction dilutes viewers' morals, the influence newspapers' party affiliations may exert, and so forth.

The conception of communication as ritual, on the other hand, is based not on the spatial dimension, but is a temporal metaphor. Here, the role of communication is not to effect change or to exert influence, but, on the contrary, to construct and maintain a shared and meaningful cultural realm:

If the archetypal case of communication under a transmission view is the extension of messages across geography for the purpose of control, the archetypal case under a ritual view is the sacred ceremony that draws persons together in fellowship and commonality (Ibid.:18).

Thus, the role of communication is not information, but confirmation. The effect of communication is not to change people, but to represent and confirm an underlying order; to manifest a current, but subtle social process (Ibid.:19).

Carey uses newspaper reading as his example of ritual behaviour. Newspaper reading is a ritual because it does more than communicate news. Apart from the news of sundry happenings, the newspaper has largely the same characteristics day after day. Newspapers definitely do not change the form and categories in which they represent reality from one day to the next. Under the news, so to speak, the newspaper therefore represents a continuum, a more or less stable image of the order of reality and how it can be grasped. That is to say, the newspaper tells us not what is new, but how the world around us essentially is. Newspaper reading as a ritual is therefore a question of the satisfaction of knowing that 'things', after all, have a fundamental order and structure (Ibid.:21).

Given this view of communication as ritual, 'the news' is not so much information, as it is drama. The news describes an arena of dramatic actors and activities, in which the reader is invited to take part (if only vicariously). Readers do imagine themselves as having a role in the drama, says Carey. Thus, the newspaper mirrors reality, but also constitutes an arena for action. The ritual of newspaper reading both constitutes and comments upon.

Carey's emphasis on communication as a ritual practice opens - and has already opened - a number of interesting perspectives for media research. Communication is more than 'effects'. Communication may be conceived of as an act that at once constitutes reality and integrates one into reality. In other words: communication is participation, not reception.

Routine use of the radio can be explained from this perspective. Radio listening as a daily ritual re-establishes the world each day as a familiar and shared place; in effect it helps (re-)establish certain behaviours and patterns of interaction as natural, as 'right and good'. Even if the world is full of violence and chaos, the structural and stylistic regularity of radio represents changes in such a way that they are not perceived as ruptures in the continuity of things. Or, less abstractly: We want the radio to supply us with news (the transmission view), but it should be supplied in a familiar form that in no way challenges our conception of the great scheme of things. The new in the news is fine, but it should be played out in a familiar arena.

Carey presents us with a very broad perspective in which to study communication. But he does not specify what a ritual actual is, or how rituals are acted out, out there in 'empirical reality'. Nor does Carey's text tell us how to go about studying the particular role of the media in ritual communication. Carey considers all forms of communication, 
including dance, and makes no distinction between communication between parties separated in time and place (mediated) or parties communicating face-to-face.

Roger Silverstone does not explicitly define what he means by 'ritual', either, even though the concept plays a central role in his theoretical work, Television and Everyday Life (1994). Consequently, it is used rather vaguely on occasion. But Silverstone's use of the concept of ritual suggests a narrower, and thus more tangible, definition than Carey's.

According to Silverstone, rituals take place as moments in which the ordinariness of everyday life is suspended. 'Ordinariness' he defines as, "the more or less secure normality of everyday life, and our capacity to manage it on a daily basis" (Silverstone 1994:166). It encompasses the greater part of our daily existence, all that we take for granted, things we simply do without thinking or commenting on - either to ourselves or to others. This is not to say that everyday life is somehow a constant, a fixed structure that at some specified moment was set into perpetual motion. Congruent with Giddens' theory of structuration (Giddens 1984), Silverstone argues that the practices of ordinary life can be made discursive, that is, that it is possible for us momentarily to step out of the normal flow of our lives and think about the structures and positions we are busy reproducing. It is here that rituals come into the picture.

Rituals, Silverstone argues, serve as a kind of mythical reflection on the flow of dayto-day existence, which the ritual suspends, either momentarily or for longer periods of time. He is not speaking of great, ceremonial ritual, but rather "small" rituals that take place every day:

\begin{abstract}
Everyday life is marked by a continuous, predictable and unpredictable, series of shifts between the marked and the unmarked, the sacred and the profane. Daily life is studded with ritual times and spaces in and through which the insistence of the daily round is momentarily put to one side ... In each of these events and in our participation in them (with or without the media) we move perceptibly from one domain of everyday life into another, crossing a boundary or a threshold into a clearly, if often a weakly marked ritual space: a space where the intense ordinariness of the everyday is replaced by a different kind of intensity - heightened and symbolically charged. In these ritual spaces the culture of everyday life is reinforced. In our participation in them ... our place and position in the world is symbolically defined (Ibid.: 168).
\end{abstract}

The important point in Silverstone's reasoning is that even if the ritual suspends the ordinariness of everyday life, the ritual is all about everyday life and our place in it. Like Carey, Silverstone stresses the strong, mutual relationship between ritual and daily life: ritual both mirrors and creates reality through symbolic forms.

What, then, is the role of mass media in an everyday life peppered with rituals? In this connection Silverstone proposes the myth, a kind of narrative whose content and form explores fundamental aspects of human existence: the relation of life to death, of nature to culture, etc. Mythic forms of communication once took place at august, ritualized places and times, clearly distinct from everyday life. Today, Silverstone argues, modern mass media have a corresponding mythic quality. The media are full of mythic narratives which reflect on life and help to generate cultural forms which are incorporated into everyday life.

The media produce a sort of raw material, a series of narratives - news, soaps, etc. which the user of the media applies, adapts and changes. Thus, life's ordinariness is not 
only the result of direct, first-hand experience, but equally as much the product of experience and knowledge gleaned from the media.

This is the same line of reasoning as underlies Klaus Bruhn Jensen's very elucidating differentiation between "time-out" and "time-in" cultures (Jensen 1995:57-58). The concept of "time out" is borrowed from the realm of sports where it represents a (requested) pause in a game or match; Jensen uses it as a metaphor for a generally brief period of time for reflection. Important is the fact that a 'time out' always takes place within the period of play, the 'time in'. That means that 'time out' will always reflect on happenings and behaviours in the game. Used to apply to everyday life and routine media use:

[I]nstitutionalized cultural activity such as mass media use may suspend other everyday activity, but still takes place in the context of the everyday (Ibid.:57).

The culture of 'time in' is the practice of everyday life. It is here that (in Giddens' terms) agentivity and structure flow together in social practice. In 'time in', we draw on the terms and procedures which make social action possible and which integrate individuals in meaningful social relations.

Jensen regards 'time out' as "a separate social practice ... which can be identified by social agents as such. It places reality on an explicit agenda as an object of reflexivity, and provides an occasion for contemplating oneself in a social, existential or religious perspective" (Ibid.:57).

Jensen summarizes the differences between the 'time-in' and 'time-out' cultures:

\begin{tabular}{|c|c|c|}
\hline Time-in & & Time-out \\
\hline Integrated practice & $\hookrightarrow$ & Autonomous practice \\
\hline Social practice & $\hookrightarrow$ & Aesthetic practice \\
\hline The ordinary & $\hookrightarrow$ & The extraordinary \\
\hline Resource & $\hookrightarrow$ & Exposition \\
\hline Action & $\hookrightarrow$ & Representation \\
\hline
\end{tabular}

In Jensen's view "time out" is the modern media culture equivalent of what used to be acted out in rituals:

While such contemplation has traditionally been associated with religious rituals and fine arts, mass communication, certainly in a quantitative sense, is the main ingredient in time-out culture in the modern age. Time-out culture is a practice which reflects upon the nature and representation of social reality (Ibid.:57).

Both Silverstone and Jensen align themselves with Carey's definition of communication as a continuous process whereby reality is reflected, commented on and constituted. And both advance theses concerning the role mass media play in this process. In their view, rituals and time outs, respectively, involving media use take place outside the practical, social behaviour of everyday life. Jensen considers 'time out' a "separate" "occasion" in which media uses "suspend ... everyday activity". At the same time, the pause in ritual space (Silverstone) or 'time-out' culture (Jensen) has the character of something extra-ordinary, something "heightened and symbolically charged" (Silverstone 1994:168), i.e., it is a particularly intense experience. ${ }^{7}$ 
Neither Silverstone nor Jensen offer any empirical evidence of media use as a suspending, extra-ordinary experience. Silverstone speaks of "stolen moments in front of the television set" as an example of how rituals are practised in everyday life (Ibid.:168). In the example the ritual use of the media takes place when the user focuses his full attention on the content of the medium. Thus, it is a question of media use establishing a momentary - and, according to the example, individual - text-reader relation, in which the intensity of the experience and the extra-ordinariness derive from the media content. The rest of everyday life is left out.

\section{Ritual Media Use: 'Text' and 'Social Situation'}

One limitation in both Silverstone's and Jensen's theories is that ritual - or ritualistic media use only occurs when the 'classical' text-reader relationship is established. An element of the transmission view pervades Silverstone's and Jensen's conception of communication as ritual: What is sacred and extra-ordinary is the text.

This is, of course, an entirely reasonable proposition. But I contend that one can extend the concept of ritual to embrace other kinds of everyday rituals that involve the media and in which media use represents, as Carey suggests, an integrative force, integrating the user into a social reality. This contradicts Silverstone's and Jensen's notion of momentary suspension of social reality, albeit Silverstone and Jensen repeatedly emphasize that the suspension is but momentary and it essentially reflects the reality it suspends.

My argument is this: If we go back to Anna«s morning routines, i.e. the quote at the start of the article, and assume that what Anna calls a ritual actually is a ritual that she and her family perform every weekday, it is certainly not a ritual that suspends reality. On the contrary, it is a ritual about creating a shared reality for all the persons present (the members of Anna's household).

The kind of ritual media use Silverstone and Jensen discuss is, as was noted, an individual activity. But the kind of ritual Anna describes is a group activity; the family's use of radio is by no means exclusive or individual. According to Anna's report, it is even unclear who switches the radio on. She says "we" (Translator's note: Actually, she says "one" (man), but it is not a reasonable translation of an oral report.) impersonal and unspecified, which indicates that the action is more or less automatic and is not given any, or very much thought. The act of switching on the radio is not an independent act, but is an integral part of the social routine.

Social uses of mass media have been studied many times before. Numerous ethnographic studies have had such a focus, perhaps the most well-known of which is James Lull's seminal article from 1980, "The Social Uses of Television" (1980/1990). There, Lull points out that "audience members create specific and sometimes elaborate practical actions involving the mass media in order to gratify particular needs in the social context of television viewing” (Lull 1980/1990.28). Thus, the media satisfy certain social needs in ways that are not directly related to the media content, but where the media are involved in social, "practical actions", as Lull puts it. In analyzing my empirical data I rely on Lull's ethnographic approach, but instead of calling Anna and her family's activities "practical actions", I take Anna's characterization literally and study the family's use of radio as part of a ritual.

The difference between media use as a practical action (in Lull's usage) and as a ritual action, respectively, is whether or not the media use gives the individual user ac- 
cess to a (micro-)social situation. Media use as a ritual action is about what steers behaviour in the social situation. Thus, whereas Lull sees media use as an individual strategy by which to reach social goals, I see it rather as a social strategy, focusing on factors that constitute the group's cohesion in the social, ritual act. Or, to put it another way: Whereas Lull's social uses approach focuses on how the individual establishes a relation to a social group, I use the concept of ritual to explore the relations among the participants in the social group.

The difference is subtle, and it is a question of degrees rather than categorical distinctions. A perhaps more pronounced difference concerns the interest attached to media content in the analysis. I argue that the concept of ritual allows the inclusion of at least some aspects of media content into 'ethnographical' analyses of media use. The reception studies contingent within Danish media research has - rightly - criticized media ethnographers for ignoring media content in their studies of media use.

In his review of James Lull's anthology, World Families Watch Television, from 1988, Klaus Bruhn Jensen complains that the contributors have totally neglected media content as an object of analysis. This is indisputably a weakness. There is, after all, as Jensen points out, a reason why the family gathers around the television set, and not the washing machine! (Jensen 1989:141) In Jensen's - and Silverstone's - approach to media use as momentary 'time outs' from the flow of everyday life, media content has a necessarily central place in the analysis. The problem with the approach is that it cannot take account of and explain media use during 'time in', i.e., when the user is not paying particular attention to what the medium is communicating.

This is not a major problem if we, at an epistemological level, recognize that reception analysis and media ethnography each cast light on their respective aspects of the phenomenon, media use. If we accept the entirely plausible assumption that media use is a multifunctional phenomenon which offers meat to any number of disciplines, we may say that reception analysis and media ethnography both study media as resources but of two different kinds. Reception analysis focuses on how an individual's use of the media gives him or her access to an external, not immediately present social context. Media ethnography, on the other hand, focuses on how use of the media provides access to micro-social situations in the user's immediate physical context.

I shall devote the remainder of this article to developing a definition of 'ritual' for use in an analysis of (micro-)social uses of media that allow inclusion of media content as an integral part of the analysis and contribute to an understanding of how everyday, routine use of the media can be involved in projects or goals that extend far beyond the time and place of the media use in question. As a point of departure in this enterprise, I should like to go back to Durkheim's classic study of ritual.

\section{Durkheim: Religion as Social Praxis}

In his classic The Elementary Forms of Religious Life (1912/1995), Emile Durkheim looks for the reasons why human beings have developed religions and observe religious rites. Durkheim's explanation, highly simplified, is that societies create religions as a means for people to join together and to demonstrate their mutuality, their solidarity. Religions are 'made' by the social acceptance of some objects and phenomena as 'sacred' as opposed to others, which are 'profane'. Religious praxis consists of worshipping, protecting and respecting these sacred objects.

It is important to bear in mind that Durkheim's primary interest is not religion per se. Even if the focus of his research was the Arunta, a tribe of indigenous people in the 
Australian hinterland, his true object of study was a more general, indeed universal, characteristic of mankind, namely, "the religious nature of man" (Durkheim 1912/ 1995:1). For Durkheim, religion is not a question of 'the divine' but of a phenomenon that is fundamentally social:

$[R]$ eligion is an eminently social thing. Religious representations are collective representations that represent collective realities; rites are ways of acting that are born only in the midst of the assembled groups and whose purpose is to evoke, maintain or recreate certain mental states of those groups (Ibid.:9).

In order to constitute a religion, three conditions must be fulfilled. First, as mentioned above, certain objects or phenomena shall be venerated as 'sacred'. Secondly, a number of rites shall exist which set out rules for how the things held sacred shall be treated. Finally, there must be a temple or sacred place, that is, a morally obligating assembly, in which the sacred objects are worshiped.

According to Durkheim, then, rituals are about establishing and maintaining social and morally obliging contracts between people. The point, for our purposes, is that this collective "mental state" cannot be achieved without the help of external "sacred objects" which are collectively venerated and which establish and maintain moral rules as to how members of the group relate to one another (Ibid.:421ff). The ritual links people to form society precisely because morality is essentially social. Participating in rituals is therefore - and in congruence with Carey's definition - participation and integration in a social reality, which the ritual continuously helps constitute.

Thus, Durkheim's concept of ritual has the following characteristics: The ritual establishes a common focus ("the sacred object") and a common mental state. The ritual venerates the sacred objects, and those who do not show appropriate respect will be punished in some way (symbolically or physically) by the others in the group. The penance may be a ritual in itself.

If we ignore for a moment the religious elements in Durkheim's concept of ritual and instead focus on the social and moral aspects, it is indeed possible to accept Anna's use of the word, "ritual" to describe her family's mornings. All the family members have a common focus (to accomplish all the necessary chores in time), they share a common mental state (the stress of rushing), and Anna stresses how important it is that everyone respect the common project, i.e., do the things they have to do in time. And if they do not? "Pity the soul who falls out of step..."

Anna and her family's morning activities fill the moral and social criteria of ritual by Durkheim's definition. There are, however, a number of implications of using Durkheim's definition which should be borne in mind. First of all, Durkheim describes rituals as primarily something out of the ordinary, as extra-ordinary, outside the everyday or in what Jensen would call "time out". There is nothing extra-ordinary about Anna's family's morning routine. To use our earlier terminology, the activities in question are quite definitely within "time in" - a situation in which the family members are acutely caught up in the demands of reality and have not a chance to "suspend" the flow by "stopping and thinking" about what they are doing, let alone why.

Still, I maintain that it is a ritual in Durkheim's sense of the word. There is a sacred object, a common focus and a shared mental state. What we must do, however, is to 'secularize' Durkheim so that we can recognize rituals in everyday social life. I argue that Durkheim's concept of ritual lends itself to such an application inasmuch as it includes the social and integrative dimensions of ritual, in contrast to, for example, Silverstone's emphasis on ritual as an individual and reality-suspending activity. We 
find a link between Durkheim's classical concept and the establishment of a operationalizable concept that examines ritual actions - with or without media involvement - in modern society in the work of Erving Goffman.

\section{Goffman: Updating Durkheim's Concept of Ritual}

Goffman explicitly carries on the legacy of Durkheim and explores the extent to which Durkheim's religious concept of ritual can be applied to contemporary, secularized society (Goffman 1967, 1971). Rituals exist in modern society, as well, Goffman assures us, but in contrast to traditional, religious rituals, modern ritual does not make a clear-cut distinction between the sacred and the profane. What is worshiped and respected, the sacred object, is the integrity of the individual: "In one sense this secular world is not so irreligious as we might think. Many gods have been done away with, but the individual himself stubbornly remains as a deity of considerable importance" (Goffman 1967:95). The gods are dead, but: "What remains are brief rituals one individual performs for and to another, attesting to civility and good will on the performer's part and to the recipient's possession of a small patrimony of sacredness. What remains, in brief, are interpersonal rituals" (Goffman 1971:89).

Ritual behaviour has moved out of the temple and into the micro-social behaviours of everyday life. A vestige of our sacred heritage is a respect for each others' integrity. Anyone who takes part in an interpersonal interaction is careful to make sure that neither his own nor the other's integrity is violated. Rather, efforts are made to protect it, to avoid committing a faux pas, making a fool of oneself. This kind of respect is practised in numerous rituals, some of which we may even regard as empty gestures.

But, even the smallest rituals, Goffman assures us, constitute and maintain social reality as a moral reality. Ritual interactions produce and reproduce moral 'judgments' which are internalized, tucked away in our consciousness to guide us in future situations; they help us distinguish right from wrong. Goffman's point is that society is held together by many micro-social rituals, which bring us to conform to various social mores and precepts:

One must look ... rather to the fact that societies everywhere, if they are to be societies, must mobilize their members as self-regulating participant in social encounters. One way of mobilizing the individual for this purpose is through ritual ... The general capacity to be bound by moral rules may well belong to the individual, but the particular set of rules which transforms him into a human being derives from requirements established in the ritual organization of social encounters (Goffman 1967:44-45).

Goffman considers particularly face-to-face conversations as rituals since they require both parties to accept and abide by the established mood of the conversation. He notes how a particularly successful conversation can leave one in a kind of trance (Ibid::113f).

Briefly, to sum up: Goffman holds to Durkheim's basic criteria as to what constitutes a ritual. Ritual is a social form, a mode of interaction, not a given act or content. The makings of a ritual are a common focus (the sacred object, respect for one another's personal integrity, a shared mental state or mood and a common space (compliance with the conditions pertaining to the interaction, 'keeping pace'), and negative sanctions, should one break the rules (the element of moral obligation).

Important to my argument here is Goffman's observation that rituals occur everywhere and all the time in everyday life. They are the lubricant that makes social interac- 
tion possible. Without them we would, in principle, have a state of chaos for there would be no blueprint for how to conduct oneself successfully, i.e., without constantly putting the Other's integrity at risk.

A point I would like to call attention to is that even though rituals no longer take place in a sanctuary, the ritual itself creates a special space, virtually regardless of where one happens to be. Thus, the two respective definitions of ritual that we have considered here (Silverstone/Jensen and Durkheim/Goffman) point to two different kinds of ritual spaces. Silverstone and Jensen speak of a place for reflection, a place to get perspective on social reality through contemplation. Goffman, on the other hand, sees ritual as creating a space for action, i.e., ritual is a means of participating in and becoming integrated into social reality, a kind of admission ticket to various social situations. In short, whereas Silverstone's concept of ritual emphasizes suspension, Goffman's emphasizes integration.

Of course, it is hardly a question of whose conceptualization is 'best'. The interesting thing is that we are talking about two different kinds of or aspects of ritual that, for that matter, most probably can occur at one and the same time. For example: It is entirely conceivable that one or another member of Anna's household might pause if something on the radio, for example, gave him or her cause for thought, for reflection.

Let us now return to Anna and her family's morning ritual as a ritual in Goffman's sense of the word. A ritual in which radio, too, plays a significant part.

\section{Anna's Morning as Ritual}

The basis for my contention that Anna and her family's morning activities qualify as a ritual is the presence of a sacred object that orders the family's activities. It is not the radio - or the 'text', because that is not what the family shows respect for. (On the contrary! one is tempted to say.) At first sight, it may seem that time is the object of everyone's respect; the one thing the family member cannot do is make each other late. But I propose that the ritual goes deeper than that; I propose that the sacred object is the family. The family as a morally obliging and - in principle - life-long project.

That it is a sacred object is evidenced by the fact that Anna is prepared to punish (if only symbolically) anyone who does not duly respect it. ("Pity the soul...") There is an implicit moral obligation for every member of the family to preserve the family as a social unit. This may sound rather lofty, but it is, after all, micro-actions that give social institutions their stability.

Rituals by definition always have importance that transcends the concrete situation in which the ritual takes place. We should recall that rituals always elicit some degree of self-discipline among the participants. And this self-discipline must draw on something greater than the situation at hand. This is an important point in extension of Goffman's moral concept of ritual. As sociologist Eric Rothenbuhler (1998) expresses the notion:

Ritual action is action oriented toward transcendence of the particularities of the situation in which it is performed. A ritual situation is one constructed so as to offer transcendence of the particularities of the social circumstances surrounding it (61).

Thus, we may say that Anna's family's morning ritual actualizes an ongoing common project, the preservation of the family as a consistent and coherent unit. A project which extends in both time and space, far beyond the situation any given morning, both back into the past and on into the future. A project that gives each family member enough motivation so that each takes his or her position and plays by the rules. Thus, it is in the 
ritual that material reality and idea meet and coalesce. Or, as Rothenbuhler put it: "[R]itual is a communication device for uniting the ideal and the material, the general and the particular, the cosmic and the ordinary, the past and the future, the structures of history and the happenings of individual lives" (Ibid.:64).

When the family's morning runs smoothly, like a ritual, it is because each family member 'knows' intuitively that they are taking part in a ritual, and that violations of the ritual have consequences that transcend the immediate situation. They may not necessarily describe their morning activities as a ritual (although Anna did), but they recognize the activities as a ritual and adjust their behaviour accordingly.

This suggests that rituals do more than bring individuals together in 'perfect harmony'. Rituals may perhaps serve to put aside and/or allay tensions that might exist among the participants. The ritual that Anna's family members perform each morning may therefore be seen as a momentary neutralization of all conflicts that may exist among the family members. Partly because it would be highly impractical if, for example, a son chose to rebel against his father in these few minutes before Father is to have an important meeting at the office, and partly because the ritual, more generally, serves as a means of maintaining social groups over time, despite whatever internal tensions as may exist.

When each family member adapts to the situation, they also (re-)assume their position, both in the concrete situation and in the family as social structure. Ritual actions are, as Goffman points out, a means for the individual to be integrated into a social reality, in which he or she has or is assigned various positions, depending on his or her current situation. The ritual assigns a position to all the members of Anna's family, a position they have no choice but to accept at the time the ritual takes place. One may therefore say that an element of submission is involved whenever one participates in a ritual: Participation presumes that one accepts one's position. Obviously, when the ritual is over, each is free to position him-/herself again - as a student, for example, or as an employee.

Before I proceed to consider radio's part in the ritual, I would like to state two reservations. First, not everyone in the family necessarily interprets the function of the ritual in the same way. To Anna the morning ritual may be a project of social bonding; to the others, perhaps a ritual of transition from the private into the public sphere, i.e., a daily separation rite. Different interpretations of what the ritual is about can co-exist, and it is not unlikely that one and the same person may perceive the ritual to fulfil several functions at once. Alternatively, 'the morning ritual' may comprise several smaller rituals, each of which serves its own purpose. It is important to note in this connection that all the family members are focused on the same project. Secondly, everyday rituals are not conscious or consciously constituted. They go unnoticed and will often reach consciousness only if the ritual is violated and the ritual order has to be re-established by sanctioning the transgression.

\section{The Role of Radio in the Ritual}

Thus, as we have established, radio is not the sacred object. Radio is but an instigating element in the ritual. Its contribution is to establish and maintain the mood or atmosphere that is required in order for the ritual to be performed by the participants in concert. My thesis is that the radio's presence in Anna's kitchen in the morning helps establish a ritual space through the continuous sound that emanates from it. This space is a space not for reflection, but for action; it is a space which introduces the morning 
ritual, focuses and synchronizes the family members' activities. In other words, the radio helps fulfil a precondition for the family's interaction and activities while it also serves as a 'boundary marker', marking the duration of the ritual (cf., for example, Larsen 1998).

Other everyday phenomena - a lighted candle, the aroma of fresh coffee, and so forth - can contribute in the same or similar fashions. But the radio is particularly well suited because its sound can be heard in several rooms and because its content is continuous and regular. The radio helps stage the same ritual day after day and serves as a constant reminder of 'where' and 'what' one is and that one's activities take place within a ritual framework. Thus, radio both helps initiate and helps institutionalize the ritual.

That is the function of the sound of the radio. What, then, is the role of its content? One can only speculate, but I would like to call attention to two aspects. First, the nature of radio as public discourse; secondly, the radio as a special 'pulse' or mood.

Radio broadcasting is by definition public, addressed to and accessible to all. Radio content is therefore an essentially public discourse relative to the more or less private contexts in which the medium is used. Radio's information content - be it news, entertainment or music - intrudes into a private state of existence in the morning and introduces the coming day as a social reality with special rules for social interaction. My point here is that precisely the public, civil tone of radio as a medium and its mirroring of the world as social reality is a prime reason why radio plays such a central, yet virtually unnoticed role in many peoples' mornings. Radio enters into a private room and presents a world that is open to everyone, thereby conveying a kind of parasocial feeling of community, which also affects our behaviour vis-à-vis others in our surroundings. Switching on the radio is to enter into a shared world, a world one also shares with those in one's immediate surroundings. Thus, the radio is well suited to establishing a common frame around a ritual, which in essence presumes a common mental state and focus of attention.

The other dimension relating to content is the pulse, rhythm and atmosphere of the medium. American sociologist Randall Collins has reviewed a series of interesting studies which show that human interaction can be synchronized down to the level of the most subtle gestures (Collins 1988:202f), so subtle that they can only be registered by filming interacting people at a rate of 24 frames per second and then playing the film in slow motion. The film sequences reveal that partners in interaction synchronize their gestures rhythmically: they nod their heads, blink, etc., in accordance with the rhythm of the conversation they are carrying on. The degree of synchronization may vary, but generally it becomes more intense over the course of the conversation. Other studies have found that partners in conversation adjust their voices (tone, loudness, tempo, etc.) so as to establish a common vocal atmosphere. In other words, individuals entering into a social situation adjust their behaviour in a mutual fashion, even down to the bodily, phsycological level, which gives the social interaction a common rhythm or pulse. ${ }^{8}$

The establishment of this common pulse is confirms and intensifies the parties' attention and involvement in a manner that is characteristic of ritual. The individuals are 'united' and are kept in the special realm that the ritual constitutes. The rhythmic synchronization in interaction is not conscious. It is a behavioural, social-bioloogical competence of very subtle expression.

One can only speculate as to the function this behavioural conformity may serve. One thesis suggests that a common rhythm helps make the interaction more predictable. One can sense how the interaction is progressing, one feels the 'beat' and receives 
signals as to whether and in what ways one should 'follow along' and 'keep the pace' in the interaction. Another theory suggests that the common rhythm, once achieved, produces an intensity that is strived for in social interaction, which is one of the main reasons why people like to participate in rituals and why ritual actions, large and small, give rise to feelings of solidarity and belonging (Ibid.:203).

In my view, radio's ability to create an atmosphere and to facilitate feelings of belonging is a somewhat overlooked element in radio research. I suggest that the tone, tempo and pulse of radio contributes to the social synchronization and intensity that can arise between listeners in one and the same room, such as Anna and her family. It is an aspect that can partly explain the regulating and non-content oriented use of radio in everyday life. A hypothesis for further study is that radio may be used to regulate the atmosphere or mood and thereby the space of interaction.

\section{Conclusion}

The overarching premise in this article is a conviction that media use is not always a matter of the relation between a 'reader' and a 'text'. Many of those who study media use in everyday life have reached that conclusion. When one asks a user of mass media what they use the media for, only a part of their use can be explained in terms relating to media content. It is my contention that some of this other, unexplained use involves a ritual function. The kinds of ritual that especially interest me are those where neither the medium nor its content have the status of 'sacred object', but where medium and content are instigating elements in the unconscious rituals of everyday life. These are rituals that are symbolic in nature and confirm and comment on aspects of social reality that do not always relate directly to the media content. The media are instigators in the sense that they help constitute the ritual by creating a shared mood or mental state which organize the participants' attention and behaviour.

The definition of the concept of ritual which I have chosen and applied may be problematic. For, if we follow Goffman's definition of ritual as being the mortar that holds society together, it is then hard to say what kind of behaviour is not a ritual. Goffman's concept represents a radical expansion of the concept which can make it difficult to operationalize. My view is that it is quite possible to distinguish between rituals, on the one hand, and habits or routines, on the other. First, rituals are social and have the purpose of integrating individuals into the group. Second, the behaviour of members of the group are organized around a sacred object, be it material or symbolic.

As I use the concept, I focus on rituals in micro-social contexts. This is not because I discount macrocontextualization of human behaviour. Further analyses will show whether the concept of ritual may establish an analytical link between micro-and macro-analyses of behaviours like media use. Rituals are not givens; existing rituals can be broken and actions can be ritualized and assume social importance far beyond the concrete action itself. The study of rituals and ritualizations in everyday life is thus a way to identify permanent and, not least, varying 'sacred objects' in society (such as in the family), how they are venerated in rituals, and the power relationships that exist between the participating parties.

One area for further study is to see how different content genres may correspond to different ritualized genres of actions (Lindlof 1988:98). That is to say, to study how listeners' criteria for choosing to listen to given radio programmes at given times 'agree with' the activities they perform parallel to listening. An approach that combines use 
and content can, I believe, produce interesting insights into the deeper aspects of radio's integration into everyday life.

\section{Notes}

1. Gallup, $2^{\text {nd }}$ quarter 1999.

2. Some of the ideas and examples presented in this article form part of a more extensive article I am writing together with Thomas Tufte, University of Copenhagen. That article treats rituals in everyday media use based on data gathered in Denmark and Brazil (Larsen \& Tufte, in progress).

3. The statements about radio use that I make use of in this article come from a qualitative study, in which I interviewed people about their use of radio in everyday life. The quotes from radio users derive from this study, as well. The study was carried out in collaboration with Danmarks Radio. The findings are reported in Larsen (1995).

4. That one relies on stereotypes regarding things done routinely, 'without thinking', is nothing new. Berelson got the same kind of responses in 1949, when he asked people why they missed their newspaper (due to a strike). Berelson commented on the responses: "To miss the newspaper for its 'serious' news value seems to be the accepted, if not automatic thing to say" (Berelson 1949:116).

5. This interpretation may be seen as an extension of, for example, Bausinger's (1984) and Nordenstreng's (1972) observations that the act of media consumption (newspaper reading and television viewing, respectively) is at least as important as the concrete information derived from the media. The ritual behaviour confirms that the world is still there in its usual state and, secondly gives the individual a sense of fellowship with the millions of other who (he or she knows) are doing the same thing.

The media's role in establishing ontological security is described in Larsen (1997), where, in a phenomenological perspective. Alfred Shutz' concept of 'horizon' is applied to explain how the media help to constitute different frameworks of knowledge and experience around day-to-day activities. The article points out that people use the media to demarcate different horizons around their activities, which allows them to control how and to what extent the outside world can penetrate into the realm of the activity at hand.

6. Goffman's concept of 'framing' is very useful in describing how media use helps to define various situations in everyday life. See, for example, Larsen (1998).

7. Both Silverstone's concept of 'ritual' and Jensen's 'time out' are reminiscent of the reflective state which phenomenologist Alfred Schütz so simply and appropriately call "stopping and thinking", a process whereby we step out of the undifferentiated progress, or durée, of everyday life in order to think over one or another phenomenon and thereafter return, more "knowing" and "competent", to the flow of life again (Schütz 1974:53).

It is the same notion as underlies anthropologist Victor Turner's concept of the liminial experience in ritual (cf. Larsen \& Tufte, in progress). Both Silverstone and Jensen refer to Turner.

8. Collins refers to studies by McClelland (1985) and Gregory (1983), among others.

\section{References}

Bausinger, H (1984) Media, Technology and Daily Life. Media Culture and Society 6:343-351.

Berelson, B (1944) What 'Missing the Newspaper' Means. In Lazarsfeld, P F \& Stanton, F N (eds.) Communications Research 1948-1949. New York: Harper \& Brothers.

Durkheim, E (1912/1995) The Elementary Forms of Religious Life. Glencoe: The Free Press.

Carey, J W (1989) Communication as Culture: Essays on Media and Society. Boston: Routledge

Collins, R (1988) Theoretical Sociology. New York: Harcourt, Brace \& Jovanovich.

Giddens, A (1984) The Constitution of Society. Cambridge: Polity Press.

Goffman, E (1967) Interaction Ritual: Essays on Face-to-Face Behaviour. Chicago: Pantheon.

Goffman, E (1971) Relations in Public: Microstudies of the Public Order. Reading/Fakenham: Penguin Books.

Gregory, S W Jr (1983) A Quantitative Analysis of Temporal Symmetry in Microsocial Relations. American Sociological Review 48:129-135.

Jensen, K B (1989) J Lull (ed.): World Families Watch Television [Review, in Danish]. Mediekultur 12.

Jensen, K B (1995) The Social Semiotics of Mass Communication. London: Sage.

Larsen, B S (1995) Lyden af hverdag: En unders $\phi$ gelse af radiobrug og hverdagsliv [The sound of everyday life: A study of radio use]. København: Københavns Universitet, Institut for Film- og Medievidenskab, Speciale. 
Larsen, B S (1997) Media Use and Everyday Life. In Koivisto, J \& Lauk, E (eds.) Journalism at the Crossroads: Perspectives on Research. Tartu (Estonia): University of Tartu and Tampere (Finland): University of Tampere.

Larsen, B S (1998) Media Situations: A Situational View on Media Use in Everyday Life. In Audiovisual Media in Transition. Copenhagen: University of Copenhagen, Dept. of Film and Media Studies. Sekvens 98.

Larsen, B S \& Tufte, T (in progress) Is there a Ritual Going on? Exploring the Social Uses of Media.

Lindlof, T (1988) Media Audiences as Interpretive Communities. In Anderson, J (ed.) Communication Yearbook 11. Newbury Park, CA: Sage.

McClelland, K (1985) On the Social Significance of Interactional Synchrony. Grinnell College, Dept. of Sociology (unpublished paper).

Nordenstreng, K (1972) Policy for News Transmission. In McQuail, D (ed.) Sociology of Mass Communication. Harmondsworth: Penguin.

Rothenbuhler, E W (1998) Ritual Communication: From Everyday Conversation to Mediated Ceremony. Thousand Oaks, CA: Sage.

Schütz, A (1974) The Structures of the Life World. Norwich: Heinemann Educational Books Ltd.

Silverstone, R (1994) Television and Everyday Life. London: Routledge. 